CIC. Cuadernos de Información y Comunicación

ISSN: 1135-7991

http://dx.doi.org/10.5209/ciyc.69714

\title{
Ulises en la redacción. Indicios, periodismo y cultura de masas
}

\author{
Héctor Fouce Rodríguez ${ }^{1}$
}

Evaluado: 24/05/2020 / Aceptado: 30/05/2020

Resumen. Este artículo propone analizar el periodismo como una forma de conocimiento ligada al desciframiento de indicios y al establecimiento de hipótesis que guíen la investigación a través del proceso inferencial. Se recupera la idea de que existe una inteligencia práctica basada en la inferencia y la anticipación que los griegos llamaron metis y que marcó tanto los inicios de la medicina como de la retórica. También se establecen las conexiones entre estas formas antiguas de descriframiento de los signos y los conceptos de índice y de abducción en la semiótica de Peirce, analizando el lugar que el hábito, la duda y la creencia tienen a la hora de orientar las inferencias. Finalmente, se ponen en acción estos conceptos mediante el análisis de las investigaciones periodísticas sobre los abusos sexuales del clero católico en Boston, relatadas en la película Spotlight, de Tom McCarthy.

Palabras clave: indicios; semiosis; metis; inferencia; abducción; periodismo.

\section{[en] Ulysses in the newsroom. Signs, journalism and mass culture}

Abstract. This article proposes to analyze journalism as a form of knowledge linked to the deciphering of evidence and the establishment of hypotheses that guide the investigation through the inferential process. The idea is recovered that there is a practical intelligence based on inference and anticipation that the Greeks called metis and that marked both the beginnings of medicine and rhetoric. The connections between these ancient forms of deciphering the signs and the concepts of index and abduction in Peirce's semiotics are also established, analyzing the place that habit, doubt and belief have when guiding inferences. Finally, these concepts are put into action by analyzing journalistic investigations into the sexual abuse of Catholic clergy in Boston, recounted in Tom McCarthy's movie Spotlight.KEY WORDS: indexes, semiosis, metis, inference, abduction, journalism.

Keywords: indexes, semiosis, abduction, metis, inference, journalism.

Sumario: 1. Presentación. 2. El periodismo como discurso sobre los hechos. 3. El periodista como rastreador de indicios. 4. Inteligencia práctica. 5. Spotlight: inferencias contra el sentido común. 6. Conclusión. Referencias.

Cómo citar: Fouce Rodríguez, H. (2020). Ulises en la redacción. Indicios, periodismo y cultura de masas, en CIC. Cuadernos de Información y Comunicación 25, 77-94. 


\section{Presentación}

Nuestro momento cultural parece estar caracterizado por la idea de que vivimos en un medio comunicativo tóxico, contaminado con mentiras y "hechos alternativos" (Rodríguez Ferrándiz, 2018), ahogados en burbujas de filtro (Pariser, 2017) construidas por algoritmos (O’Neil, 2016) que se aprovechan de nuestra constante derrama de datos personales para ofrecernos únicamente aquellas cosas y personas que nos agradan (Rodríguez, 2013). Las redes sociales prometían democratización y eliminación de los gatekeepers (Gilmore,2006), iban a permitir a los receptores convertirse también en autores (Jenkins, 2008) y generarían una esfera pública más diversa y participativa, pero han creado un entorno comunicativo en el que el disenso se transforma en confrontación y el diálogo muta en guerra cultural (Bernabé, 2018; Soto Ivars, 2017)

Frente a esta realidad, se alzan múltiples voces que reclaman la vuelta a la centralidad de los hechos y, por ende, la recuperación del periodismo como lugar de construcción de la realidad común, inspirado por mecanismos de control de las fuentes y equidad en el acceso. Las redes ofrecen opiniones y bulos, pero los periodistas ofrecen hechos, vías de acceso a la realidad, no tergiversados por intereses, manipulaciones o algoritmos. Sin embargo, es necesario reconocer que buena parte de las fake news de mayor alcance en tiempos recientes llegaron desde los medios y no desde las redes. Las armas de destrucción masiva nunca fueron descubiertas en Irak, de modo que el New York Times se vio obligado a despedir a Judith Miller por haber publicado información sin pruebas. La autoría de ETA de los atentados del $11 \mathrm{M}$ de 2004 fue descartada por los tribunales. Frente al seguidismo gubernamental de muchos medios españoles, y ante las presiones de Moncloa, los corresponsales extranjeros enviaron una carta al gobierno en la que defendían su independencia: "no hacen falta advertencias de como tenemos que redactar nuestras noticias. Eso es nuestra responsabilidad, no la del gobierno" (Adolf, 2004).

\section{El periodismo como discurso sobre los hechos}

El problema, por supuesto, es que un hecho dista mucho de ser una realidad existente por si misma: aceptamos que la noticia es el resultado de un proceso experto modelado por un entorno profesional e inserto en un contexto cultural, y por eso reclamamos ciertos límites y ciertos derechos a la labor de los periodistas. Tampoco la materia prima de la que se nutre el periodismo, la realidad, se nos muestra en bruto: su percepción requiere de una serie de operaciones para darle sentido.

La propia definición de qué es un hecho es complicada. El periodista de Sunday Times Nicholas Tomalin (cit. en Davies, 2008:112 ) explica que "la idea de un hecho es simplista. Los hechos no son sagrados: en el momento en que un reportero empieza a escribir su historia, ha seleccionado unos hechos y no otros y así ha distorsionado la situación. Decir que el trabajo de un periodista es reportar los hechos es como decir que el trabajo de un arquitecto es juntar ladrillos - cierto, pero inexacto".

Ahondando en esto, Mark Thompson (cit. en Davies, 2008:147), director ejecutivo del New York Times (y antes Director General de la BBC), explica que las noticias no más que el relato de hechos son un "objeto cultural sofisticado". Todas las sociedades han construido procedimientos narrativos para reportar sucesos que 
han ocurrido en el pasado, pero el artefacto cultural conocido como noticia, producto de una institución llamada periodismo, es el resultado de una serie de procesos económicos, tecnológicos y culturales (Chalaby, 1998). La invención del periodismo que reconstruye Chalaby es la historia de la creación de un método de procesamiento de los hechos para darles forma narrativa. El periodismo nace cuando las noticias dejan de ser partidistas y aparece la ambición de contar la realidad de forma objetiva, para lo que se operativizan una serie de procedimientos. La tan mentada objetividad, recuerda Chalaby (1998: 129 ss.), no es un atributo del periodista, sino del método.

Con el tiempo, estos procedimientos se han transformado, se han sofisticado y, en ocasiones, se han pervertido. Los mismos procedimientos que, al "separar hechos de emociones" (Chalaby, 1998: 129), sirvieron para legitimar el discurso periodístico y situarlo en "una posición externa al campo político, desde un punto de vista que se reclama no involucrado directamente en el conflicto político" (Chalaby, 1998: 110), han generado rutinas periodísticas que permiten sacar adelante el trabajo sin preocuparse demasiado por los peligros que este entraña. Como señala Tuchman (1999: 201), el periodista es "un hombre de acción que debe decidir inmediatamente la validez, fiabilidad y verdad de algo para abordar los problemas que impone la naturaleza de su trabajo -el procesamiento de la información que llamamos noticia, un producto de consumo fungible que se elabora diariamente". La objetividad se convierte en un ritual estratégico:

los periodistas afrontan esas presiones subrayando su "objetividad", arguyendo que los peligros pueden minimizarse si se siguen unas estrategias informativas que identifican con las "noticias objetivas". Asumen que si todos los periodistas recopilan y estructuran "hechos" de un modo independiente, sin prejuicios e impersonal, los cierres podrán cumplirse y evitarse las demandas por difamación (Tuchman, 1999:202).

La esfera pública (Habermas, 2002) nace como un espacio conectado con el gobierno pero independiente, en el que una nueva república de ciudadanos libres (básicamente hombres burgueses, como ha señalado Frazer (1993) y ha admitido el propio Habermas) discuten los asuntos comunes en términos de igualdad. La independencia de esa esfera pública está siempre amenazada por las interferencias interesadas del poder político (y económico). Como señala Davies (2008:121).

los reporteros confían en las fuentes oficiales. En buena medida es porque están bien organizadas... y proporcionan materiales listos para usar. Pero, sobre todo, es porque los reporteros saben que están a salvo de ataques si siguen la línea oficial. La línea oficial es segura.

Muchos son los pecados, delitos y faltas de una institución centenaria sin cuya participación no habrían sido posibles ciertos hechos vergonzantes de la historia (de la Guerra de Cuba a la Guerra del Golfo) pero tampoco la creación de las democracias modernas y la participación política de las masas. No es posible olvidar que la lucha por la libertad de prensa va de la mano de la lucha por la representación política. Chalaby $(1998,85)$ recuerda que hasta 1800 no se permitió a la prensa el acceso a la Cámara de los Comunes. Durante un siglo, los parlamentarios habían combatido todo intento de hacer públicas sus deliberaciones: en 1738 una norma declaró que 
era una gran indignidad y una notoria quiebra del privilegio ("high indignity and a notorious breach of privilege") reportar lo dicho en la Cámara.

Desde Marx, muchos filósofos y analistas políticos han argumentado que la publicación de las actas del Parlamento es un sine qua non para que un régimen sea definido como no autoritario. La publicación de los debates introduce la posibilidad de la crítica y, por otro lado, la participación de los ciudadanos en el proceso de toma de decisiones (Chalaby, 1998:85).

Más de un siglo después, eliminado su acceso privilegiado a la información y su difusión con la llegada de internet (Jarvis, 2015) y socavada la legitimidad de las democracias modernas, el periodismo no podía sino entrar en crisis. Las vías de salida aún no están claras y el moderado éxito de algunos modelos no puedo ocultar la masiva desapacición de cabeceras y de puestos de trabajo periodísticos.

\section{El periodista como rastreador de indicios}

La reconstrucción de los medios informativos en la era de la desinformación masiva deberá ir de la mano de reclamar que el periodismo es una forma de saber y de acceso al conocimiento. En esta reconstrucción, los hechos tienen un lugar central, pero de la mano de los procedimientos que permiten no solo conocer los datos sino también asegurar su rigor y darles sentido, para lo cual es necesario justificar teóricamente la validez de ciertas prácticas y de la lógica que las sostiene.

Es necesario recordar que la prensa nace casi al mismo tiempo que la ciencia moderna, al amparo de la Ilustración. Cuando hay ciencia hay duda y hay método. En la base de la ciencia está la idea de que el conocimiento debe ser separado de la creencia y que aquel solo es accesible a través de la observación que permita construir teorías que a su vez den lugar a experimentos observables que demuestren la validez de la teoría.

Nuestra concepción moderna de la ciencia es heredera del empirismo filosófico, que, según Jaeger (cit. en Castañares, 2014: 30) "es hijo de la medicina griega, no de la filosofía griega". Son los doctores helénicos los que por primera vez definen un método que rechaza las adivinaciones para afirmar que su actividad es describir signos por medio de los cuales es posible hacer conjeturas. "La techne médica consiste en una serie de reglas que permiten conciliar la observación del cuerpo humano con el razonamiento y reducir así el campo del azar" (Castañares, 2014: 25). Se trata de observar los síntomas que presenta el paciente e interpretarlos de acuerdo con unas reglas que la experiencia ha permitido acumular. La observación no se produce en el vacío: la observación que da origen al conocimiento siempre está dirigida por unos conocimientos previos que permiten construir teorías. De este modo, el empirismo heredero de la galénica

lleva a cabo una estrecha articulación del paso, el presente y el futuro. El conocer a través de lo que se observa es lo que da carácter específico al "arte médico", es una sabia mezcla de anámmesis (memoria, experiencia acumulada a través del tiempo), aísthesis (observación de lo que ocurre) y prognosis (previsión de lo que va a ocurrir) (Castañares, 2014: 27-8). 
La percepción, el instante del presente, está marcada tanto por la memoria como por las hipótesis y teorías sobre el futuro: no es un mero proceso físico, sino un proceso de intelección.

La percepción es interrogativa y condicional y siempre se rige (incluso cuando no se es consciente de ello) por un principio de apuesta... Ya Peirce era consciente de que la percepción es un proceso indiciario... El hecho de que se produzca sin esfuerzo no invalida la existencia del mecanismo como tal (Eco, 2000:55).

No existe, para el ser humano, la realidad en bruto, sino una realidad a la que es necesario dar sentido: describirla, establecer causalidades y diagnósticos y poder anticipar el futuro en forma de pronósticos. La realidad es cognoscible en tanto nuestra experiencia del pasado permita establecer guías de actuación para el futuro. Como ha señalado Habermas (1987: 188), "mientras la estructura del mundo pueda suponerse constante, mientras mis experiencias anteriores sigan siendo válidas, se mantiene en principio mi capacidad de operar sobre el mundo".

No existen por tanto hechos crudos que den lugar automáticamente a las noticias, sino eventos percibidos en cierta manera de acuerdo a ciertos sistemas de expectativas que son procesados en función de ciertos intereses para dar lugar al texto periodístico. El proceso de interrogar a la realidad en busca de orientación sobre la relevancia de los sucesos cotidianos no es automático, sino que requiere del esfuerzo y la habilidad. El signo es la herramienta que los humanos podemos usar para conocer la realidad. Pero, como señala Eco (2000):

un signo no se basa en la igualdad, en la correlación fija establecida por el código, en la equivalencia entre expresión y contenido, sino en la inferencia, en la interpretación.... No corresponde al modelo "A=B" sino al modelo "si A entonces..." El signo es lo que siempre nos hace conocer más.

La habilidad del periodista, del reportero y del investigador radica en percibir los hechos dentro del continuo informe que es la realidad, leer esta como signo de algo que, por una razón u otra, interesa a sus lectores o espectadores. Si los antiguos interpretaban la naturaleza como un libro que se ofrecía al lector avezado (Castañares, 2018) el periodista reporta sobre la sociedad leyendo esta de forma inquisitiva, asumiendo que el periodismo es precisamente contar las cosas que alguien no quiere que se cuenten. De este modo, la realidad social deja de ser transparente y se aparece como un rompecabezas que hay que reconstruir uniendo indicios dispuestos de forma desordenada aquí y allá: la correcta interpretación de estos indicios, convertido en hechos a través de la narración periodística, crearía las noticias.

Alcmeón, otro representante de la escuela de medicina griega, ya lo enunció en su momento: "de las cosas invisibles y de las cosas mortales los dioses tienen una certeza inmediata, pero a los hombres les corresponde proceder por indicios" (cit. en Castañares, 2014:23). Para Aristóteles (cit. en Castañares, 1999:38), "la cosa cuya existencia o producción lleva en sí misma la existencia de otra cosa, ya fuera anterior o posterior, es lo que se llama indicio, pues indica que la otra cosa ha ocurrido o existe". El indicio de los griego fue conceptualizado por Peirce (C.P. 2305) como índice, "un signo, o representación, que se refiere a su objeto no tanto debido a su similitud o analogía con él, ni porque esté asociado con caracteres generales 
que ese objeto posee, sino porque está en conexión dinámica (también espacial) tanto con el objeto individual, por un lado, como con los sentidos o la memoria de la persona para la que sirve como signo, por otro lado". Más adelante, Peirce explicará que el índice representa al objeto debido a que existe una conexión entre signo y objeto. "No importa si la conexión es natural, artificial o simplemente mental" (C.P. 8.368).

El índice pertenece a la categoría de la segundidad, es el signo que establece relaciones causales y temporales. Aunque el índice tiene una función importante tanto en el funcionamiento de las imágenes (Abril, 2007; Peñamarín, 1998) como en la organización del lenguaje (Peñamarin, Lozano, Abril, 1982) nos interesa en este caso en su vertiente más física, en tanto evidencia de una actividad o una acción. Es un signo "que pertenece más que al mundo de las palabras, al de las cosas, es decir, al mundo de la naturaleza y del comportamiento humano. Pero las inferencias que desencadenan esos signos tienen que ser expresadas mediante argumentos "puestos en discurso" (Castañares, 1999:36). Esta continuidad entre la experiencia sensible y la expresión es especialmente importante en el caso del periodismo, cuya especificidad discursiva se basa en una peculiar construcción textual que hace desaparecer al narrador de los hechos en nombre de la objetividad.

Sin duda el más famoso intérprete de indicios es Sherlock Holmes, a quien Eco y Sebeok (1989) han dedicado un volumen analizando sus aventuras a la luz de la semiótica peirceana. Del mismo modo, una nada despreciable cantidad de narraciones de la cultura de masas ha explotado la tentación del ser humano inteligente de leer los signos como apuestas o acertijos en busca de respuesta. De los registros forenses de CSI a las novelas de Jo Nesbo, de las series de abogados como The good wife a las ambientadas en hospitales como House, buena parte del guión descansa en el juego de desciframiento de los índices y de la elaboración de distintos tipos de inferencias. Las historias de investigaciones periodísticas, verídicas o ficcionales, tienen también un lugar importante en nuestra cultura audiovisual y su interés radica en seguir el proceso de descubrimiento de los hechos por parte de los periodistas. Desde clásicos como Todos los hombres del presidente (All the President's Men, Alan J. Pakula,1976) que narra la investigación del caso Watergate, hasta las más reciente Los pápeles del Pentágono (The Post, Steven Spielber, 2017) o Spotlight (En primera plana, Tom McCarthy, 2015), los espectadores han podido presenciar como la vida pública se hace mejor cuando los periodistas siguen los indicios para investigar y darles forma de reportajes que dan a conocer a los ciudadanos las inmundicias de sus gobernantes o los crímenes de sus vecinos.

Bien es cierto que esta misma pulsión por el desciframiento está detrás de las numerosas teorías conspiratorias que pueblan nuestro ecosistema cultural, una tendencia que está lejos de ser reciente, como prueba la enorme influencia del panfleto antisemita Protocolo de los sabios de Sion, sobre el que Eco construyó una de sus novelas de inspiración semiótica (El cementerio de Praga, 2010). Un buen ejemplo de las modernas teorías conspiratorias es el documental Behind the curve (2018) que sigue a un grupo de personas que han construido su identidad en torno a la idea de que existe una conspiración desde hace siglos para convencernos de que la tierra es redonda, cuando en realidad es plana.

Por otra parte, podemos pensar en otra versión de la inferencia, que es el trabajo que se hace para evitar, precisamente, que las conexiones causales sean establecidas. Cuando un político corrupto crea una red de testaferros o un entramado empresarial 
como los relatados en los Panamá Papers es perfectamente consciente de que cada una de sus acciones puede ser construida como un signo de su actividad delictiva, y por eso se esfuerza en tapar sus rastros. La aparición de soplones que está en la base de casos como los Panamá Papers, Wikileaks o Cambridge Analítica permite a los periodistas activar esos "sentidos y memoria" de los que habla Peirce al definir al índice en busca de patrones, nombres y números que puedan dar cuenta de quienes son los verdaderos propietarios del dinero o actores de la actividad ilegal.

En el inicio de la actividad periodística está el acontecimiento. Los estudiantes de periodismo están hartos de escuchar que es noticia si un hombre muerde a un perro, no si un perro muerde a un hombre. Es posible discutir hasta qué punto esto es un problema para el periodismo. Para Chalaby (1998:83), al ser la política un proceso continuo, la aparición del "fetichismo del presente" del discurso periodístico a principios del siglo XX hizo que los tiempos del mundo político y el de los medios dejasen de estar en sincronía. La escasa atención de los medios a los procesos, frente a la fascinación por los hechos, fue uno de los puntos de crítica de polémico informe McBride de 1980. Y la centralidad del acontecimiento, junto con la omnipresencia de los medios de comunicación y las redes sociales, ha creado una cultura del evento y del pseudo-acontecimiento cuya única finalidad es captar la atención.

Moura de Oliveira (2018: 24) defiende que la semiosis de la noticia conecta el objeto/acontecimiento con el interpretante/periodismo y genera el signo/noticia. El acontecimiento irrumpe en la superficie de la historia (primeridad) pero para que el acontecimiento ocurra "es preciso que se manifieste en su discontinuidad y que haya sido identificado de acuerdo con una cierta descripción y en función de un contexto de sentido, para que se le pueda asociar un pasado y un futuro" (Queré, cit. en Moura de Oliveira, 2018: 29). Las expectativas, la previsión de verosimilitud, orienta la percepción de los periodistas a la hora de dar forma a los hechos.

Tuchman (1998: 212) cita el ejemplo del joven John F. Kennedy, enviado a cubrir las elecciones inglesas tras la guerra mundial: cuando reportó que Churchill perdería las elecciones, recibió "un cañonazo de Hearst acusándome prácticamente de estar chalado". Esa posible derrota "contradecía el sentido común americano al insistir en que un político popular, que había conducido con éxito a su país en medio de una guerra no iba a ser reelegido. Su "experta opinión" cuestionaba lo que "todo el mundo sabía" y "daba por sentado". Así que no era "factual".

El acontecimiento, por tanto, no está dado sino que se construye a través de las prácticas periodística en interacción con las lógicas de la vida social. El periodista no puede conocer a priori cuál de los múltiples acontecimientos que tienen lugar a su alrededor alterará la continuidad del presente para demandar su atención. Son precisamente la experiencia y la habilidad profesional, conceptualizados como "olfato periodístico", lo que permite identificar algo como un indicio que conduce a una información.

La necesidad de convertir un fenómeno en signo de otra cosa fue uno de los primeros problemas que enfrentaron los médicos griegos en su práctica semiótica. El hékaston era un acontecimiento observable "del que aún no se sabe si debe introducirse en el cuadro diagnóstico de una enfermedad porque se ignora si tiene o no relación causal con lo que la produce" (Castañares, 2014: 26). Solo algunos de estos

se convierten en un indicio, algo visible que nos remite a algo que no se ve, pero con lo que, conjeturalmente, podría estar conectado. El semeîon puede, sin em- 
bargo, adquirir el sentido de prueba, de tekmerion, con lo que la inferencia deja de ser una mera conjetura para convertirse en la inferencia segura de la deducción (Castañares, 2014: 26).

De modo análogo, podemos identificar dos momentos en el trabajo periodístico: primero, la identificación del acontecimiento que merece la atención del reportero. Segundo, un trabajo de comprobación de hechos y de creación de continuidades y causalidades que convierten los indicios en pruebas.

Ahondando en la complejidad de la relación del índice con la realidad, Peirce refirió a los índices degenerados,

ese tipo de signos que son interpretados como teniendo una relación real con su objeto, pero al no tratarse de un hecho actual, sino más bien del pasado, actúan como los iconos: por similitud con otros hechos ya conocidos y, por tanto, de los que ya se tiene una representación. Son signos que no dan información, sino de los que se puede extraer información (Castañares, 1999: 47).

Recordemos que los médicos griegos referían a un sistema de reglas para interpretar los signos y que además la experiencia y la memoria, del mismo modo que ahora, eran un elemento fundamental en la práctica galénica. Del mismo modo, el periodista (y el lector de periódicos) no se enfrentan cada día a la realidad como algo novedoso, sino que acumulan conocimientos y saberes, así como prejuicios, presuposiciones o hábitos. La aplicación del método junto con la experiencia acumulada (en forma de contactos, legitimidad y peso de la opinión propia) son las armas del periodismo de calidad.

\section{Inteligencia práctica}

El juego del ratón y el gato entre delincuente y policía o políticos corruptos y periodistas, que ha alimentado tantas películas y series, se basa en la lectura de los índices y la elaboración de inferencias que llevan a una acusación ante los tribunales o a la publicación de información en los medios. En ambos casos, y para cada una de las partes, se moviliza un tipo de inteligencia que los griegos antiguos llamaban metis. Como explican Detienne y Vernant (1988:11) en su libro Las artimañas de la inteligencia:

la metis es una forma de inteligencia y pensamiento, un modo de conocer. Implica un conjunto complejo, pero muy coherente, de actitudes mentales y de comportamientos intelectuales que combinan el olfato, la sagacidad, la previsión, la flexibilidad de espíritu y la simulación, la habilidad para zafarse de los problemas, la actitud vigilante, el sentido de la oportunidad, habilidades diversas y una experiencia largamente adquirida.

Metis es la primera esposa de Zeus y se complementa con la otra esposa Temis, que posee el saber categórico, omnisciente, que domina el mundo de las regularidades y las normas. Metis representa el saber relacionado con "un futuro que se presenta aleatorio... hipotético o problemático" (Detienne y Vernant, 1988: 99). Domina la 
sorpresa y la artimaña: tiene el poder de adoptar todas las formas. Su hijo estaba llamado a transformarse en rey de dioses y destronar a Zeus, como este había hecho con su padre. Consciente de esto, cuando Metis estaba encinta, Zeus logra convencerla de que se haga pequeña y la engulle: incorporada a su propia sustancia, le otorga en todo instante el conocimiento del incierto porvenir que va a hacerle dueño del curso fluctuante y aleatorio de los acontecimientos (Detienne y Vernant, 1988: 105). Zeus instaura así un mundo nuevo: "gracias a su Metis interior... su ojo, que no se cierra jamás, se mantiene sin cesar en continua alerta. Ante él, no hay ataque ni artimaña: no existe metis que pueda sorprenderle" (Detienne y Vernant, 1988: 108).

La metis es una forma de conocimiento práctico, una inteligencia basada en el hacer cuya base es la lectura e interpretación de los signos de manera que permita ganar ventaja. Es la inteligencia del cazador capaz de seguir los pasos de la presa a través de sus huellas y rastros, la habilidad del marinero para leer las estrellas y adaptarse a los vientos. Detienne y Vernant (1998: 18 ss) la ilustran con un ejemplo de la Ilíada: Antíloco, el joven auriga, logra ganar la carrera a pesar de que sus caballos son más lentos que los de su experimentado adversario Agamenon: es capaz de aprovechar un estrechamiento de la pista para obligar a frenar a los caballos de su oponente. "Su metis de auriga le sugiere una maniobra... que va a permitirle invertir una situación desfavorable y triunfar sobre otros más fuertes que él" (Detienne y Vernant, 1988: 19). Vemos aquí condensados los rasgos de la metis: el triunfo de la astucia sobre la fuerza; su desarrollo en un horizonte temporal incierto, en el que los acontecimientos pueden tomar diferentes sentidos; su saber astuto, identificado con aprovechar las oportunidades proporcionadas por una lectura sagaz de la realidad y sus posibilidades.

Ulises es sin duda el héroe clásico de la metis: la Odisea es la narración de cómo Ulises debe movilizar todas sus habilidades para llegar a su tierra. Habilidades que tienen que ver con el manejo del lenguaje, como cuando tras cegar al cíclope le dice que ha sido "Nadie" su agresor, de manera que los demás gigantes no pueden identificar al culpable. O tretas, como cuando se ata al mástil para poder guiar el barco sin sucumbir a la llamada de las sirenas. Recurre al disfraz para acercarse a su casa en Ítaca y hacerse una idea de cuál es la situación. Ya en la Ilíada, Ulises, llamado por Homero "el de los muchos ardides", muestra que no es sólo la fuerza y la valentía lo que ganan las guerras, al concebir la estratagema de construir el caballo de madera para poder atacar la ciudad desde dentro en vista de lo inútil del asedio que ya dura 9 años. "Ulises es experto en ardides variados y jamás carece de recursos para salir de apuros en todo género de dificultades" (Detienne y Vernant, 1988: 25).

La metis no está ligada únicamente a los trabajos físicos, sino que se extiende a aquellos que deben vérselas con engaños, triquiñuelas, ocultamientos y dobles sentidos. También el mundo de la retórica, así como el de la medicina, son mundos gobernados por Metis: "la enfermedad y el discurso son fuerzas no menos hostiles e inquietantes que el mar, el fuego o el metal en fusión; enfrentarse a ellos consiste en prever siempre la ocasión fugitiva para engañar a esas potencias polimorfas" (Detienne y Vernant, 1988: 278).

El retórico era, para los griegos, uno de los poseedores de metis: al trabajar no sobre la verdad, sino sobre la argumentación, a partir de uso de los tropos, el retórico es capaz de transformar la realidad y mostrarla desde sus intereses en función de lo que el auditorio previamente conoce y da por bueno. "La retórica se alza con fuerza como medio para poner orden - y también sacar ventaja- en el río revuelto de la 
polis" (Castañares, 1999: 33). Al perder su vinculación con la lógica y la dialéctica queda reducida a una disciplina clasificatoria y desaparece en el siglo XIX, hasta que es rehabilitada como arte de la argumentación (y no como tratado de la ornamentación) por autores como Perelman y Olbrechts-Tyteca (1989).

El periodismo va a heredar de los retóricos la desconfianza que suscitan aquellos capaces de manejar las palabras; acusar al periodismo de ser "mera retórica" o de "contar historias" no deja de ser una defensa preventiva ante esas habilidades. La desconfianza en los medios de comunicación -que España tiene el dudoso honor de liderar con frecuencia entre los países de nuestro entorno- tiende a interpretarse como una medida negativa de la calidad de las democracias. Pero como explica Rosanvallon (2008), las democracias son sistemas de equilibrios, en las que unas instituciones se vigilan entre sí: el poder democrático se basa tanto en la vigilancia como en la resistencia, es un perpetuo esfuerzo de los gobernados para limitar los abusos de los poderosos. Una función de los movimientos sociales es actuar como vigilantes de los poderes públicos, del mismo modo que lo hace la prensa. Pero esta, al postularse como cuarto poder, no puede sustraerse a la vigilancia y la desconfianza de la ciudadanía, alertada de la tendencia de los poderosos a alinear sus intereses y estrategia (véase el relato de David Jiménez (2019) en sus pocos meses como director de El Mundo)

Heredero del retórico en nuestra cultura contemporánea es en buena medida el abogado que debe convencer a un jurado o un juez. El amplio arraigo de la institución del jurado, formado por legos en derecho que solo emiten un juicio de culpabilidad o inocencia en ausencia de duda razonable, genera alegatos que la ficción se ha encargado de amplificar, como es el caso del caso OJ Simpson. La imagen icónica de este mediático juicio fue la de su abogado sosteniendo un guante que no entraba en la enorme mano de su cliente, y que la acusación había presentado como prueba de cargo al grito de "if it doesn't fit, you must acquit" (si no encaja, deben absolverlo).

La capacidad de dar con testigos, desmontar o establecer coartadas, convertir hallazgos en pruebas, forman parte de la metis del abogado. Pero también la capacidad de identificar casos similares y manejar la jurisprudencia precisa forman parte de ese conjunto de habilidades prácticas. En la película Una cuestión de género (On the basis of sex, Mimi Leder, 2018) se muestra como la joven abogada Ruth Bader Ginsburg (después jueza del Tribunal Supremo de EEUU) logra una sentencia que deroga leyes machistas presentando al tribunal lo injusto del caso de un hombre discriminado, tras intentar sin éxito equiparar su defensa de los derechos de las mujeres con las luchas de los negros por los derechos civiles. Esta capacidad de dar la vuelta a la realidad, de asirla por lugares imprevistos, de encontrar huecos por los que penetrar en una realidad escurridiza y no fijada, es propia de los mejores abogados. Es metis.

$Y$ es que la metis es el tipo de inteligencia necesaria para entendérselas con "realidades fugaces, movedizas, desconcertantes y ambiguas, que no se prestan a la medida precisa, al cálculo exacto o al pensamiento riguroso" (Etinenne y Verlant, 1988, 11). En el mundo líquido en el que vivimos ahora, las continuidades y leyes de la ciencia que una vez se postularon como modelo para entender las múltiples dimensiones del mundo no parecen ser el único modelo posible de entender la realidad.

El periodismo de investigación es precisamente un espacio que se las tiene que ver con esas realidades ambiguas y movedizas. Nada hacía presagiar que la irrupción 
de unos ladrones en el edificio Watergate estuviese ligado a las actividades ilícitas del presidente Nixon, pero la intuición de los periodistas del Washington Post generó una de las investigaciones periodísticas más famosas de todos los tiempos. Al descubrir que los que pretendían ser unos ladrones de época monta eran defendidos por abogados ligados al Partido Republicano, analizaron los perfiles de cada uno de los intrusos y ahí arrancó una investigación que estuvo a punto de descarrilar en numerosas ocasiones debido a la desconfianza de sus superiores en el periódico.

Como señala Eco (2000: 56), existe un tipo de inferencia que se basa en una implicación material que "no se pronuncia sobre la validez epistemológica del vínculo entre antecedente y consecuente... A veces el consecuente es producto de una mera hipótesis... Gran parte de los descubrimientos científicos se basan en inferencias hipotéticas de este tipo, que Peirce llama abducciones ". De este modo, la abducción "representa el intento aventurado de trazar un sistema de reglas de significación que permitan al signo adquirir su propio significado" (Eco, 2000: 61)

No deja de resultar sorprendente que ni Aristóteles ni ningún otro lógico fuese capaz de percibir que existe un tipo de inferencia que complemente a la inducción y la deducción, un tipo "exigido por la misma estructura de los silogismos" (Castañares, 1999: 40). Fue Peirce quien determinó que existe un tipo de inferencia que "permite introducir nuevos elementos en el discurso" (Castañares, 1999: 40), usando los procesos de investigación a manera de campo de pruebas. "La abducción es el procedimiento inferencial que nos permite inventar una hipótesis... Puede decirse que la abducción busca una teoría... y permite la generalización partiendo de los casos particulares" (Castañares, 1999: 40). En este "pensar hacia atrás", "la abducción se convierte en un proceso de adivinación muchas veces efectivo, que nos permite la reconstrucción de lo ya ocurrido y la previsión de lo que va a ocurrir" (Castañares, 1999: 41). Este pensar creativo que aúna pasado, presente y futuro es el mismo que reivindicaban los galenos griegos: un saber preñado de metis.

\section{Spotlight: inferencias contra el sentido común}

Buena parte de este elenco de habilidades prácticas, compartidas por retóricos, investigadores y abogados confluyen en la figura del periodista de investigación, una figura tan engrandecida en la ficción como escasamente sustentada por los intereses económicos tras el periodismo, al ser caro y generar problemas. El investigador es, como Ulises, el de los muchos ardides, aquel capaz de moverse en diferentes ambientes, de rastrear testimonios y conseguir pruebas.

Estas habilidades inferenciales están bien ejemplificadas en la película Spotlight, Oscar a la mejor película en 2015. Es la historia de la investigación de los periodistas de Spotlight (la más antigua unidad de investigación en los medios escritos estadounidenses) en torno a los abusos sexuales a menores por parte de curas católicos en la ciudad de Boston: revelaron que la jerarquía católica había creado un sistema para ocultar los abusos, acallar a las víctimas y permitir a los sacerdotes abusadores seguir en activo. La investigación abrió camino a numerosas denuncias en el seno de la iglesia católica alrededor del mundo, obligó a dimitir al cardenal Bernard Francis Law y mereció un premio Pullitzer en 2003.

Mike Rezendes es el reportero que ejemplifica el saber práctico de la metis en la película, de la mano de su relación con otro personaje escurridizo, el abogado de las 
víctimas de abusos Mitchell Garabedian. Una columna en la que se comentan sus acusaciones contra el cardenal Law es la puerta de entrada a la investigación. Ya en su primer encuentro (escena 30$)^{2}$, vemos que Rezendes no se rinde ante los formalismos: harto de esperar a Garabedian, se cuela en el despacho cuando su secretaria se retira a por café. Su primer encuentro con el abogado está mediado por la artimaña y la capacidad de aprovechar la oportunidad

Garabedian lleva años enfrentado a la iglesia y a su poder en Boston y ha desarrollado complejas estrategias legales para obtener el acceso a documentos confidenciales. Buena parte de la acción de la película transcurre mientras los abogados del Boston Globe sostienen un litigio en los tribunales para lograr que se hagan públicos los documentos que prueban las acusaciones contra los sacerdotes y la implicación de la jerarquía católica en su enmascaramiento. Rezendes va conociendo la lógica legal de los procesos y de las estrategias de Garabedian al tiempo que se gana su confianza: así llega a conocer que, independientemente del resultado del proceso abierto, existe la posibilidad de acceder a algunos de los documentos de manera sencilla.

Pero, una vez zanjada la cuestión legal, Rezendes encuentra escasa voluntad cooperadora en el registro del juzgado (escena 131): se le niegan los documentos y, cuando exige hablar con el supervisor, se lo sacan de encima alegando que no está. El hombre de acción que el periodista deber ser, como señalaba Tuchman, aparece entonces: Rezendes pide ver al juez de guardia, frente a cuya puerta debe esperar largamente, para solicitar el acceso a los documentos que la moción legal desclasifica. Y en esta escena (136) se muestra la continuidad entre los diferentes dominios de la metis, de la acción a la argumentación.

Juez Volterra: Estos documentos que solicita son registros muy sensibles.

Mike Rezendes: Con todo el respeto, señoría, esa no es la cuestión. Los registros son públicos.

Juez Volterra: ¿Dónde está la responsabilidad editorial en la publicación de registros de esta naturaleza?

Mike Rezendes: ¿Dónde está la responsabilidad editorial de no publicarlos?

Con este breve intercambio de frases, Resendez moviliza tanto el respeto por las formas y la jerarquía -evita enfrentarse al juez, apelando simplemente a la legalidad- y la defensa de los valores del periodismo, la necesidad de publicar aquello que algunos no quieren que se sepa. Ya de vuelta al registro, Resendez tendrá de nuevo que vérselas con el obstruccionismo de los funcionarios: no puede quedarse los documentos, tiene que fotocopiarlos, pero reprografía está cerrada. Finalmente, saca todo el dinero que lleva en el bolsillo: "le doy 83 dólares si me deja usar su fotocopiadora" (escena 137).

El acceso a la realidad no solo se logra a través de las fuentes que cuentan su experiencia: buena parte de la vida de nuestras sociedades está codificada por medio de datos. Los sucesos que narra la película están ambientados en 2002, cuando internet estaba en sus comienzos y no existía aún lo que ahora llamamos periodismo de datos. Pero tanto los directorios de la diócesis (en papel) como la colección de todas las informaciones sobre pederastia y abusos clericales que el Globe había publicado en los últimos años tiene un importante papel como signos que orientan la investigación.

Para señalar la acción de la película tomaremos como referencia el número de cada escena en el guión 
La escena 31 muestra el trabajo artesanal para rescatar todos esos clips del archivo, llevado a cabo por las mujeres del servido de documentación a través de microfilms y carpetas de recortes. Las dos siguientes escenas (32 y 33) muestran el trabajo del equipo con esos materiales: es ahí donde se empiezan a conocer otras denuncias y se identifica además la figura de uno de los abogados de la iglesia que ha contribuido a acallar la mayoría de los casos.

Durante la primera mitad de la película, la investigación avanza a través de inferencias inductivas: los periodistas conocen las identidades de víctimas y, al analizar la información disponible en los directorios, encuentran que todos los sacerdotes envueltos en acusaciones son trasladados con frecuencia. El directorio califica de "retiro por enfermedad" cada uno de estos movimientos. Son capaces de rastrear cada nombre y las circunstancias de sus traslados, pero aún no tienen una teoría que dé sentido al comportamiento de la jerarquía eclesiástica.

En este punto es importante la figura de Richard Sipe, un personaje del que solo escuchamos la voz a través de conversaciones telefónicas. Sipe es un cura que abandonó los votos para casarse con una monja y que después de formarse como psicoterapeuta trabajó durante años en un centro de tratamiento de curas pederastas. Desde entonces, y a pesar de los intentos de la iglesia de desacreditar su investigación, estudió el fenómeno de la pederastia: es quien pone en conocimiento del equipo de Spotlight la existencia de estos centros y el que les ofrece la regla que necesitaban para cambiar la orientación de su investigación: calcula que un $6 \%$ de los sacerdotes católicos es un abusador. "Hemos estado usando los directorios para confirmar a los curas malos. ¿Y si lo hacemos al revés? ¿Y si usamos los directorios para identificar a los curas malos?", propone Robby Robinson, el director del equipo. A partir de la estadística de Sipe, calculan que puede haber 90 curas envueltos en casos de abusos: hasta ese momento habían identificado 15; tras el análisis del directorio, llegan a la cifra de 87. Aquí se manifiesta la adbucción como proceso de adivinación, capaz de guiar la reconstrucción de lo ya sucedido y de anticipar lo que puede ocurrir: el tiempo inestable e inseguro de la metis.

La investigación da un giro decisivo cuando los testimonios van confirmando la hipótesis: no son "manzanas podridas" sino un sistema organizado de encubrimiento en el que están envueltas las más altas autoridades eclesiásticas. En una reunión del equipo con Marty Baron, editor del Boston Globe, este giro es convertido en directriz editorial (escena 94). Sacha Pfeiffer, la única reportera, expone que "los números indican claramente que la jerarquía estaba involucrada"; el editor responde:

Eso es todo lo que hacen, indican... Nos meteremos en la misma pelea de gatos en la que nos metimos tras el caso Porter, que hizo mucho ruido, pero cambió las cosas muy poco. Tenemos que centrarnos en la institución, no en los sacerdotes individuales. Práctica y política. Muéstrame que la Iglesia manipuló el sistema para que estos tipos no tuvieran que enfrentarse a cargos. Muéstrame que ponen a esos mismos sacerdotes de vuelta a las parroquias, una y otra vez. Muéstrame que esto era sistémico, que venía de arriba abajo.... Vamos a por el sistema.

De este modo, podemos dividir la lógica de esta investigación (y la trama de la película) en dos momentos: durante la primera parte de la investigación se van acumulando evidencias y, de manera abductiva, se van formulando hipótesis que den un sentido unificado a los datos que se reúnen. "La abducción actúa cuando debo 
interpretar ... huellas, síntomas e indicios... Por tanto, la abducción representa el intento aventurado de trazar un sistema de reglas de significación que permitan al signo adquirir su propio significado" (Eco, 2000:61).

Una vez establecida la regla, la lógica del sistema que Marty Baron quiere que revele la investigación de Spotlight, la dinámica de la investigación cambia: estamos en el momento deductivo, moviéndonos de la regla al caso y de ahí al resultado. La película nos guía a través del trabajo de reporteros de Sacha Pfeiffer y Stephen Kurkjian: recorren las calles, se citan con curas y víctimas, son amenazados y se les cierran puertas, logran el testimonio de policías (escenas 96 a 105).

En este punto es importante detenerse en el papel de Marty Baron, nombrado editor del Boston Globe en 2001. Aunque el Globe es en buena medida un periódico local, fue comprado en 1991 por The New York Times: frente a una redacción muy enraizada en la ciudad, Baron es un outsider. Las primeras escenas de la película enfatizan este rasgo. Cuando Robby Robinson se encuentra con el abogado de la iglesia Jim Sullivan, representante de la aristocracia católica de la ciudad, este comenta: "así que el nuevo editor del Globe es un hombre soltero de fe judía al que no le gusta el beisbol" (escena 38). Cuando visita al cardenal Law para presentarle sus respetos como nuevo editor (una costumbre en la católica Boston), Baron se muestra notablemente incómodo. Frente a los reiterados ofrecimientos de la ayuda de la iglesia, Baron responde al cardenal "en mi opinión, para que los periódicos puedan hacer bien su trabajo es mejor que vayan por libre" (escena 48).

El abogado Garabedian es el otro personaje principal que no forma parte del mundo católico de la ciudad. Garabedian es armenio y empatiza con la posición de Baron como editor judío en un contexto cultural ajeno. En una conversación con Rezendes, explica: “de repente todo el mundo se interesa por la iglesia católica. ¿Por qué? Porque para eso se necesita a un outsider... Esa gente hace que los demás sintamos que no pertenecemos a la ciudad. Pero escuche mis palabras, señor Rezendes: si hace falta un pueblo para criar a un niño, también hace falta un pueblo para abusar de él" (escena 76).

Este lugar de conflicto entre dos mundos de sentido es lo que Lotman (1996) entiende como la frontera de la semiosfera: ahí es donde se generan las novedades, donde se transforman las seguridades de los viejos sistemas en nuevas propuestas. Para Peirce, "nuestras creencias guían nuestros deseos y conforman nuestras acciones" (Peirce[ $\left.\left.{ }^{3}\right], 1988: 14\right)$. El sentimiento de creer es un indicativo de que en nuestra naturaleza se ha establecido un hábito que determinará nuestra conducta (ibid.). Y los hábitos guían nuestra interpretación del mundo, puesto que "lo que nos determina a extraer, a partir de premisas dadas, una inferencia más bien que otra es un cierto hábito de la mente" (Peirce,1988: 10).

Como ha recordado Peñamarín (2017: 29), la esfera pública es un espacio de inscripción, memoria y temporalidad compartida, un archivo común. Desarrollamos nuestras inferencias e interpretamos los indicios en el marco de una enciclopedia y con un horizonte de expectativas que está determinada por ella. Para Eco (2000: 73) "interpretar un signo significa definir el segmento de contenido transmitido, en sus relaciones con otros segmentos derivados de la segmentación global del contenido... Con la posibilidad... de poner en tela de juicio el modo en que la forma del

Hemos manejado la edición de La fijación de la creencia en castellano de José Vericat, disponible en https:// www.unav.es/gep/FixationBelief.html. Los números indican la sección del texto de dónde proviene la cita. 
contenido ha segmentado el continuun". La película propone que solo la presencia de alguien con perspectivas ajenas a la cultura católica de Boston y al peso histórico de la iglesia en la vida de la ciudad posibilitó que la misma comunidad que se volcaba en educar a los niños fuese capaz de volver la vista ante los abusos repetidos a lo largo de décadas.

El contrapunto de Baron es Robby, nacido y criado en Boston y con buenas relaciones con la aristocracia católica. A lo largo de la película vemos como sus amigos le presionan para detener la investigación y dejar de confiar en el criterio de su editor. Se apela a su lealtad a la comunidad, que está en conflicto con su ética profesional. Pero según avanza la investigación, Robby se siente más indignado con la actitud del círculo de poder que rodea a la iglesia católica y más ajeno a sus dinámicas de camaradería y complicidad. Peter Conley es otro de los abogados cercanos a la iglesia que intenta frenar las indagaciones del equipo de Robby:

Hay mucha gente aquí que te respeta, Robby, respeta tu trabajo... Es porque te preocupas por este lugar. Es por lo que haces, es quien eres. Pero la gente necesita a la Iglesia más que nunca en este momento. Puedes sentirlo. Y el Cardenal puede no ser perfecto, pero no podemos tirar todo lo bueno que está haciendo por unas manzanas podridas (escena 151).

Cada vez con más insistencia, interpelado por los testigos a los que implícitamente se recrimina su papel pasivo ante los abusos, Robby comienza a plantearse su grado de responsabilidad en el silencio colectivo. Según avanza la trama, los espectadores vamos sabiendo que tanto abogados como víctimas habían hecho llegar al Globe información sobre casos de pederastia, información que fue sistemáticamente ignorada. En diferentes escenas $(93 \mathrm{~A}, 123)$ el espectador va siendo partícipe de las dudas del equipo sobre quién fue responsable del deficiente seguimiento de las denuncias. Del mismo modo, los diferentes encuentros que Robby sostiene con sus amigos católicos para confirmar datos acaban con un cruce de reproches que siempre se vuelven contra él. Cuando logra por fin el testimonio off the record del abogado Jim Sullivan, que su editor considera imprescindible para publicar el reportaje, este lo despide airado: "Tienes razón, Robby, todos sabíamos que algo estaba pasando. ¿Y dónde estabas tú? ¿Por qué tardaste tanto?” (escena 163).

La escena (165) en la que el equipo cierra la publicación del reportaje con el editor da respuesta a todas estas preguntas. Ante las recriminaciones de los reporteros a la inacción del abogado que confirmó la lista de sacerdotes acusados, Robby se pregunta:

¿Qué hay de nosotros? Teníamos todas las piezas. ¿Por qué no lo conseguimos antes?... Teníamos a Saviano, a Barrett, a Geoghan. Teníamos los directorios en el sótano.... MacLeish nos envió una carta acusando a 20 sacerdotes, hace años. Sacha encontró el recorte. Justo después del caso Porter, en diciembre del 93. Enterramos la historia. Nada de seguimiento... Fui yo. Acababa de tomar el control de la sección de Local. No lo recuerdo en absoluto. 


\section{Conclusión}

Si el proceso de dar sentido al mundo depende de nuestra habilidad de extraer inferencias y este "no es tanto un don natural como un arte prolongado y difícil" (Peirce, 1988: 2) que viene determinado por "un cierto hábito de la mente" (Peirce, 1988: 10), podemos observar en esta escena final el proceso de cambio de hábitos que experimenta Robby. La existencia de evidencias anteriores a la investigación de 2002 y su escaso seguimiento muestra que los hechos dependen extraordinariamente del contexto en el que son producidos y percibidos para cobrar sentido. Lejos de ofrecer una interpretación natural, los indicios requieren de un proceso inferencial que tiene mucho de creativo y que en buena manera depende de la capacidad del intérprete para cuestionar sus sistemas de sentido.

La creencia es un estado de "tranquilidad y satisfacción que no deseamos eludir" (Peirce, 1988: 15) pero que es desafiado por la duda, que genera inquietud e insatisfacción. La indagación que surge en respuesta a esta inquietud es orientada por la adbucción, la capacidad de generar hipótesis creativas que permitirán después ser comprobadas mediante el proceso inductivo. Podemos establecer dos conclusiones que se derivan de estas ideas en torno al trabajo periodístico y que han sido ejemplificadas en Spotlight.

La primera es que la capacidad de generar inferencias y de interpretar indicios depende en buena manera del entorno social y cultural y de su estabilidad. Los entornos sociales homogéneos tienden a eliminar la duda y por tanto la posibilidad de que surja la indagación. La importancia de los entornos multiculturales, poblados por diferentes perspectivas, ha sido analizada tanto en el ámbito de la decisión política (enfatizando el valor del disenso frente a las cámaras de eco) (Sunstein, 2003) como los entornos sociales y económicos (Florida, 2008)

En el ámbito del periodismo, observamos como la inserción de los periodistas en sus comunidades tiene un importante valor, ya que permite generar estructuras de confianza que darán lugar a agendas de contactos. Pero, sin la presencia de estímulos externos, el estado de tranquilidad que el hábito genera impide el surgimiento de la duda. En este contexto, los periodistas ven limitada su capacidad para desarrollar las inferencias que permiten identificar en el plano discurrir cotidiano aquellos sucesos que tienen valor como hechos y merecen un seguimiento.

En segundo lugar, hemos observado que las habilidades que los periodistas necesitan para desarrollar su trabajo se inscriben en el plano de la inteligencia práctica que los griegos llamaban metis. El periodista desarrolla esta inteligencia práctica tanto en el ámbito de la acción (en su relación con las fuentes, en su manejo de los datos, en su colaboración con abogados en el caso analizado) y en el ámbito del lenguaje, puesto que la investigación periodística siempre requiere de una puesta en discurso que apela a un conjunto de convenciones enunciativas.

Apelar al periodismo como una práctica de interpretación de indicios inspirada por la metis es reivindicar su papel como fuente de conocimiento sobre la realidad en un periodo histórico en el que la sobreabundancia de discursos oscurece el acceso a la realidad. En un momento en que se cuestiona hasta la validez de los métodos experimentales para obtener conocimiento, no podemos renunciar a un modelo inferencial que "aunque no siempre posee valor probatorio, no por ello deja de ser racional“" (Castañares, 2014: 30). Y, frente a la tentación de reducir el mundo a aquellas cosas que conocemos de primera mano, como reacción a la creciente complejidad de 
la realidad circundante, es preciso reivindicar "la posibilidad de un saber científico que, gracias al método semiótico-inferencial, es capaz de reducir la multiplicidad de los hechos a síntesis significativas" (Castañares, 2014: 27).

Reconocer las limitaciones del conocimiento no es lo mismo que renunciar a conocer. Asumir la incompletitud de nuestro método no significa que no sea útil. El trabajo periodístico es por naturaleza incompleto: está siempre a la contra de una hora de cierre que obliga a trabajar rápido y abre el camino a la aparición de errores. El método periodístico, las obligaciones de contraste, identificación y equilibrio de las fuentes, el uso de estructuras narrativas específicas, son al tiempo corsés y herramientas para minimizar esos errores: corresponde a los profesionales desarrollar la inteligencia práctica para manejar esas limitaciones de forma creativa. Ulises no podía ignorar la voluntad de los dioses, los vientos del océano o la magia de la voz de las sirenas: pero podía diseñar estrategias para lograr sus objetivos.

Es necesario reconocer que tanto la naturaleza de la realidad como las herramientas para acceder a ella hacen que el conocimiento sea complejo. Como comenta Marty Baron rebatiendo las acusaciones de Robby contra sí mismo por no haber sido capaz de dar sentido a todos los indicios que estuvieron frente a él a lo largo de los años: "a veces es fácil olvidar que pasamos la mayor parte de nuestro tiempo tropezando en la oscuridad. De repente, una luz se enciende, y los reproches van y vienen sin parar".

\section{Referencias}

Abril, G. (2007). Análisis crítico de textos visuales : mirar lo que nos mira. Madrid: Síntesis. Adolf, S. (2004). Carta del Círculo de Corresponsales al Secretario de Estado de Comunicación en funciones [Press release]. Retrieved from https:/cadenaser.com/ ser/2004/03/16/espana/1079398221_850215.html

—. Behind the curve. (2018). In D.-v. Productions (Producer).

Bernabé, D. (2018). La trampa de la diversidad: como el neoliberalismo fragmentó la identidad de la clase trabajadora. Tres Cantos: Akal.

Castañares, W. (2014). Historia del pensamiento semiótico 1. La antigüedad grecolatina. Madrid: Trotta.

Castañares, W. (2018). Historia del pensamiento semiótico 2. La Edad Media. Madrid: Trotta.

Castañares, W. (2019). La prueba y la probabilidad retórica. En S. Barrena \& J. Nubiola (Eds.), Escritos sobre C. S. Peirce (pp. 211-243). Pamplona: EUNSA.

Chalaby, J. K. (1998). The invention of journalism. Basingstoke: Palgrave.

Davies, N. (2008). Flat Earth News. London: Chatto \& Windus.

Detienne, M., \& Vernant, J.-P. (1988). Las artimañas de la inteligencia. Madrid: Taurus.

Eco, U. (2000). Semiótica y filosofía del lenguaje. Barcelona: Lumen.

Eco, U. (2010). El cementerio de Praga. Barcelona: Lumen.

Eco, U., \& Sebeok, T. (Eds.). (1989). El signo de los tres. Barcelona: Tusquets.

Florida, R. L. (2008). Who's your city? : how the creative economy is making where to live the most important decision of your life. New York: Basic Books.

Fraser, N. (1993). Repensar la esfera pública. Una contribución a la crítica de la democracia actualmente existente. Debate Feminista(7), 23-58. 
Gilmore, D. (2006). WE the media. Grassroots journalism by the people, for the people: O'Reilly Media.

Habermas, J. (1987). Teoría de la acción comunicativa 2. Madrid: Taurus.

Habermas, J. (2002). Historia y crítica de la opinión pública : la transformación estructural de la vida pública. México: Gustavo Gili.

Homero. Ilíada: Instituto Latinoamericano de la Comunicación Educativa.

Homero. Odisea. Instituto Latinoamericano de la Comunicación Educativa.

Jenkins, H. (2008). Convergence Culture. New York: New York University Press.

Jiménez, D. (2019). El Director. Madrid: Libros del KO.

Lotman, I. (1996). La semiosfera. Semiótica de la cultura y del texto. Madrid: Cátedra.

Lozano, J., Peña-Marín, C., \& Abril, G. (1982). Análisis del discurso : hacia una semiótica de la interacción textual. Madrid: Cátedra.

McBride, S. (Ed.) (1988). Un solo mundo, voces múltiples. Madrid: Fondo de Cultura Económica y UNESCO.

Moura de Oliveira, F. (2018). La semiosis de la noticia. Barcelona: UOC.

O’Neil, C. (2016). Weapons of Math Destruction. New York: Crown.

Pariser, E. (2017). El filtro burbuja : cómo la red decide lo que leemos y pensamos. Barcelona: Taurus.

Peirce, C. S. (1935-58). Collected Papers, vols 1-8. In C. Hartsthorne, P. Weiss, \& A. W. Burks (Eds.), Collected Papers, vols 1-8. Cambridge, MA: Harvard UNiversity Press.

Peirce, C. S. (1988). La fijación de la creencia. En J. Vericat (Ed.), Charles S. Peirce. El hombre, un signo (El pragmatismo de Peirce) (pp. 175-179). Barcelona: Crítica.

Peñamarín, C. (2017). Mediación y mediatización de la comunicación pública. Una perspectiva pragmática. In M. Álvarez-Peralta, G. Fernández, \& M. Leia (Eds.), La mediación fragmentaria (pp. 11-36). La Laguna: Cuadernos Artesanos de Comunicación.

Peñamarín, C. (1998). Polemic Images: Metaphor and Index in the Language of Political Cartoons. VS. Quaderni di studi semiotici,(80/81).

Perelman, C., \& Olbrechts-Tyteca, L. (1989). Tratado de la argumentación: la nueva retórica. Madrid: Gredos.

Rodríguez, D. (2013). Memecracia: los virales que nos gobiernan. Barcelona: Gestión 2000.

Rodríguez Ferrándiz, R. (2018). Máscaras de la mentira: el nuevo desorden de la postverdad. Valencia: PreTextos.

Rosanvallon, P. (2008). Counter-democracy. Politics in the age of mistrust. Cambridge: Cambridge University Press.

Singer, J. y McCarthy, T. (2015). Spotlight (screenplay). Open Road Films

Soto Ibars, J. (2017). Arden las redes: la postcensura y el nuevo mundo virtual. Barcelona: Debate.

Sunstein, C. (2003). Why societies need disent. Cambridge, MA: Harvard University Press.

Tuchman, G. (1998). La objetividad como ritual estratégico: un análisis de las nociones de objetividad de los periodistas. CIC Cuadernos de Información y Comunicación; No 4 (1998/99) https://revistas.ucm.es/index.php/CIYC/article/view/CIYC9899110199A

Vega Encabo, J. (2010). Los saberes de Odiseo. Buenos Aires: Eudeba. 